\section{PERFIL DAS MULHERES ESCALADORAS BRASILEIRAS, ENTRE HOMENS E MONTANHAS}

\author{
PROFILE OF BRAZILIAN FEMALE CLIMBERS: AMONG MEN AND \\ MOUNTAINS P
}

PERFIL DE LAS MUJERES ESCALADORAS BRASILEÑAS, ENTRE HOMBRES Y MONTAÑAS C

doi' https://doi.org/10.22456/1982-8918.104869

Dimitri Wuo Pereira* <dimitriwuo141@gmail.com>

Yasmin Brito Souto Maior* <yayasoutomaior@gmail.com>

Bianca Trovelo Ramallo** <biancaramallo@gmail.com>

*Faculdades Metropolitanas Unidas.

**Faculdades Metropolitanas Unidas / Universidade Federal de São Paulo.

Resumo: A escalada apresenta riscos e desafios, exigindo habilidades físicas e emocionais. As mulheres a cada dia se apropriam desta cultura no Brasil. O objetivo da pesquisa foi traçar um perfil das escaladoras brasileiras e sua percepção sobre sua aceitação no esporte. O método utilizado foi exploratório com um questionário para 268 escaladoras. Como resultado identificou-se que as escaladoras adquirem boa qualidade de vida, pelos aspectos fisiológicos, sociais e emocionais. A prática da escalada torna a mulher confiante e autônoma dependendo do desempenho técnico e físico. A escalada, para elas, se mostra um espaço de superação que vai além do ambiente vertical. Conclui-se que o número de mulheres que pratica escalada no Brasil aumentou, demonstrando que, mesmo com situações adversas, elas seguem firmes na modalidade, buscando independência e a evolução do esporte feminino.

Palavras chave: Esportes. Mulheres. Aptidão.
Recebido em: 28-06-2020

Aprovado em: 01-09-2020 Publicado em: 27-11-2020

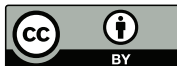

Este é um artigo publicado sob a licença Creative Commons Atribuição 4.0 Internacional (CC BY 4.0). elSSN: 1982-8918 


\section{INTRODUÇÃO}

A escalada é um esporte de aventura, sendo seu principal objetivo progredir verticalmente um obstáculo através do próprio esforço físico para superar os limites pessoais. Conforme Pereira e Armbrust (2010, p. 65): "[...] querem enfrentar e superar tanto as dificuldades de explorar a natureza quanto suas próprias limitações físicas, técnicas e emocionais". De acordo com Bertuzzi e Lima-Silva (2013), o ambiente da escalada compreende o gelo, a neve, a rocha e indoor (muros artificiais).

A escalada indoor é encontrada nas academias, clubes, escolas e casas, com agarras feitas de resina e pó mineral (areia ou semelhante) nas mais diferentes formas e tamanhos, essa modalidade surgiu na Europa como opção para se manter o treinamento nos períodos de inverno (MARINHO; BRUHNS, 2001). Hoje em dia, essas paredes são utilizadas para realização de campeonatos, pois permitem a "[...] simulação dos diferentes estilos de escalada, em especial, a escalada de velocidade, de boulder e de dificuldade" (BERTUZZI; LOMA-SILVA, 2013, p. 10), criando-se vias ${ }^{1}$ de diferentes graus de dificuldade.

Muitos praticantes utilizam as paredes artificiais para treinar movimentos de maior dificuldade, simulando vias que pretendem fazer nas rochas; outros buscam ser atletas de alto rendimento; e há aqueles e aquelas que escalam como forma de socialização e divertimento. As paredes artificiais facilitam o acesso à prática devido ao menor deslocamento do que nas montanhas, também são atividades menos arriscadas, pois o ambiente é mais controlado do que a natureza. Outros fatores, como participação brasileira em campeonatos mundiais, criação de entidades de escalada, organização de campeonatos, segundo Pereira e Manoel (2008, p. 109: "[...] nos levam a crer que a difusão dessa prática esportiva tende a se consolidar cada vez mais em nosso país".

A participação feminina também aumentou, merecendo investigação e reflexão, afinal a participação da mulher na prática esportiva nem sempre é incentivada, de acordo com Giglio et al. (2018, p. 2). "[...] o caminho trilhado pelas mulheres dentro da sociedade mundial foi construído por meio de muitas resistências, exclusões e rupturas em uma estrutura controlada por uma ideologia patriarcal". Especificamente na escalada, até o início do século $\mathrm{XXI}$, algumas pesquisas afirmavam que modalidades de risco e que exigiam muita força ou resistência não eram apropriadas às mulheres (APPLEBY; FISHER, 2005). Além desse aspecto, é evidente que os incentivos ao homem em relação à prática esportiva tornam o caminho facilitado ao universo masculino e são um obstáculo a mais que as mulheres devem enfrentar (MOURA et al. 2017).

Nesse ponto, surge o interesse de realizar esta pesquisa, que tem como objetivo descobrir a participação das mulheres na escalada brasileira traçando seu perfil e verificando as dificuldades de aceitação no esporte.

1 Vias são rotas ou caminhos para se ascender na escalada. 


\section{MÉTODO}

Foi realizada uma pesquisa exploratória com abordagem quantitativa e qualitativa devido à novidade do tema e necessidade de obter conhecimentos gerais sobre o assunto (SEVERINO, 2007). O instrumento utilizado foi um questionário online enviado através do Google formulário, com a escala de Likert (1932) adaptada para graduar opiniões das participantes do estudo em relação à sua prática. A escala, que varia de 1 a 5 , tem neste estudo o valor 1 para nenhum medo e o valor maior 5 para muito medo.

A amostra contou com 268 participantes de todo o país, com idade média de 33 anos, que assinaram o Termo de Consentimento Livre e Esclarecido, e a pesquisa foi aprovada pelo comitê de ética da Universidade Nove de Julho sob número 82.781 . A amostra foi composta por atletas de alto rendimento e por escaladoras recreativas. As participantes foram contatadas através das redes sociais WhatsApp, Instagram e Facebook, tanto pelos contatos dos pesquisadores como por convite nos grupos de escalada e de academias de escalada nas redes sociais, permitindo atingir todas as regiões do país.

A análise dos dados foi feita através do programa Excel 7.0 com média, desvio padrão e porcentagem e os dados discutidos em relação à literatura científica disponível. Uma das questões foi aberta, neste caso, foi feita a Análise de Conteúdo (BARDIN, 2008), da análise surgiram quatro categorias: Técnica; Família; Socioemocional (confiança, oportunidade, violência e assédio); Tensões entre gêneros. A discussão de cada categoria foi feita em dois momentos, um para as escaladoras que se sentem confortáveis em escalar somente com mulheres e outra para aquelas que não se sentem confortáveis em escalar somente com mulheres. A apresentação dos resultados foi dividida em dois momentos: perfil das escaladoras e percepção da aceitação no esporte e as participantes foram identificadas como sujeito $\mathrm{S} 1, \mathrm{~S} 2, \mathrm{~S} 3 \ldots$

\section{RESULTADOS}

\subsection{PERFIL DAS ESCALADORAS}

O quadro a seguir apresenta o perfil das participantes.

Quadro 1 - Idade e morfologia.

\begin{tabular}{|l|c|c|c|c|}
\hline & Idade & Altura & Peso & IMC \\
\hline Média & 33,7 anos & $163 \mathrm{~cm}$ & $57,3 \mathrm{~kg}$ & $21,5 \mathrm{Kg} / \mathrm{m}^{2}$ \\
\hline Desvio Padrão & $+/-7,7$ anos & $+/-6 \mathrm{~cm}$ & $+/-7,4 \mathrm{~kg}$ & $+/-2,1 \mathrm{~kg} / \mathrm{m}^{2}$ \\
\hline
\end{tabular}

Fonte: criado pelos próprios autores.

Os dados apontam para pessoas maduras, com grande variação de idade e IMC normal. 
Quadro 2 - Anos de prática, grau médio de escalada, quantidade de prática por semana e sensação de medo na escala Likert (escala que vai de 1 para nenhum medo até 5 para muito medo).

\begin{tabular}{|l|c|c|c|c|}
\hline & Experiência & Nível técnico & Frequência & Medo \\
\hline Média & 4,6 anos & Entre $5^{\circ}$ e $6^{\circ} \mathrm{grau}$ & $2,18 \mathrm{X} / \mathrm{semana}$ & $3,46(1-5)$ \\
\hline Desvio padrão & $+/-3,3$ anos & $+/-1,7 \mathrm{grau}$ & $+/-1,12 \mathrm{X} /$ semana & $+/-1,06$ \\
\hline
\end{tabular}

Fonte: criado pelos próprios autores

No Quadro 2 verifica-se que a amostra é bastante heterogênea, são pessoas experientes com nível técnico médio, pois a graduação na escalada vai do $3^{\circ}$ ao $11^{\circ}$ grau, demonstrando uma prática de atividade física regular e que expõe seu medo de forma natural numa modalidade de risco com apenas dez mulheres que afirmaram nenhum medo. Os dados apresentam ainda que $85 \%$ delas realizam outra atividade física além da escalada, revelando constância e variação na prática esportiva.

Numa estratificação da amostra, na qual se separaram as escaladoras com maior nível técnico (aquelas com $8^{\circ}$ grau de escalada, ou mais, sendo um total de $8,9 \%$ ) obteve-se IMC de $19,5 \mathrm{~kg} / \mathrm{m}^{2}$, frequência de três a quatro vezes por semana e a percepção do medo delas ficou entre 2 e 3 . Foi possível identificar também que $58 \%$ praticam a escalada há quatro anos ou menos e $42 \%$ tem cinco anos ou mais de experiência, com $17,5 \%$ de escaladoras com dez anos ou mais.

A escalada em rocha é realizada por $87 \%$ das entrevistadas e $52 \%$ escalam em paredes artificiais (ginásios e academias). A pesquisa verificou que $60 \%$ preferem a prática da escalada esportiva, sendo o estilo predominante e $40 \%$ das entrevistadas preferem em paredes artificiais (escalada indoor). Uma curiosidade que surgiu nos dados foi que $1,1 \%$ das entrevistadas praticam big wall (escalada em paredes com mais de um dia de duração).

Clubes, associações e projetos universitários são o ponto de encontro de $62 \%$ das participantes e os estados de São Paulo e Rio de Janeiro concentram 46\% do total das praticantes. Olhando por regiões verifica-se que o SE registra $61,5 \%$ do total, S têm $21 \%$, CO 10,6\% e N e NE reunidos contêm 6,9\%.

Em relação aos benefícios desenvolvidos na escalada encontrou-se, na categoria física $87 \%$ revelam aumento de força, seguido pelo equilíbrio, $66 \%$, coordenação motora, $54 \%$, e flexibilidade com $44 \%$. Na categoria socioemocional $81 \%$ apontaram as amizades, $76 \%$ confiança, $73 \%$ coragem e concentração e $72 \%$ melhora na autoestima. Destaca-se que a maior dificuldade descrita por $43 \%$ das mulheres na prática é a necessidade de força, superior ao medo, que ficou com $42 \%$.

\subsection{A ACEITAÇÃO NO ESPORTE}

Este estudo procurou identificar as tensões na prática esportiva da escalada entre homens e mulheres. O Quadro 3 mostra os resultados. 
Quadro 3 - Questões relacionadas à aceitação na escalada.

\begin{tabular}{|l|l|c|}
\hline Pergunta & Resposta & $\%$ \\
\hline 1. Quem apresentou a escalada? & Figura masculina & $60,5 \%$ \\
\hline 2. Como foi a recepção dos homens no início? & Forma positiva & $74,5 \%$ \\
\hline \multirow{2}{*}{ 3. Sente discriminação por parte dos homens? } & Não & $54 \%$ \\
\cline { 2 - 3 } & Sim & $41 \%$ \\
\hline 4. É encorajada a montar via em parede artificial? & Sim & $60 \%$ \\
\hline 5. Homens te incentivam a evoluir tecnicamente? & Sim & $92,5 \%$ \\
\hline \multirow{2}{*}{ 6. O que você faz tanto quanto os homens? } & Guiar em ponta de corda & $54,5 \%$ \\
\cline { 2 - 3 } & Conquistar vias em rocha & 11,2 \\
\hline \multirow{2}{*}{ 7. Sua principal parceria na escalada? } & Homens e mulheres & $46 \%$ \\
\cline { 2 - 3 } & Homens & $38,5 \%$ \\
\cline { 2 - 3 } & Mulheres & $15 \%$ \\
\hline \multirow{2}{*}{$\begin{array}{l}\text { 8. Sente-se confortável para viajar para escalar só } \\
\text { com mulheres? }\end{array}$} & Sim & $88,5 \%$ \\
\hline
\end{tabular}

Fonte: criado pelos próprios autores.

A pergunta 8 solicitava justificativa, e a Análise de Conteúdo traz as respostas por categoria, primeiro daquelas que se posicionaram negativamente e depois positivamente nesta questão:

Resposta negativa, por categoria.

- Técnica: "Homens têm mais qualidade técnica no que tange ao manuseio do equipamento" (S121). "Muitas mulheres que conheço não guiam" (S237). "Homens têm mais prática e mais conhecimento de resgate em altura" (S135). "Pouquíssimas mulheres guiam, acho que isso tem grande impacto na integração feminina na prática do esporte (S162).

- Família: "Eu pratico escalada com meu marido e ele me passa mais confiança" (S226). "No momento atual desejo estar com a família" (S218).

- Socioemocional: "Não conheço nenhuma mulher que escala" (S86), "tenho medo de assédio e violências" (S246). "Não há segurança em alguns lugares" (S237).

- Tensões entre gêneros: "Não me sinto incluída nos grupos femininos" (S90). "Na hipótese de um caso fortuito a força masculina pode ser melhor explorada" (S257). "Talvez pela criação machista sinto mais segurança com uma figura masculina" (S198).

Resposta positiva, por categoria.

- Técnica: "As mulheres têm o mesmo conhecimento e técnica que os homens" (S52). "Eu tenho curso de escalada e conheço os procedimentos de segurança e confio escalar com outras mulheres" (S80). "Sinto que eles têm mais tempo para treinar (...) grande parte das mulheres tem filhos para cuidar. É uma comparação injusta" (S248). "Na primeira experiência de escalada clássica só com uma amiga foi bem desafiador, ficamos com medo no meio da via e decidimos abandonar (...) nas viagens seguintes já foi super confortável" (S178). 
- Família: "Em todos meus quinze anos de escalada eu nunca fiz uma viagem só com mulheres, por ser casada com um escalador, porém tenho vontade de desvincular minha escalada da dele" (S17).

- Socioemocional: "Procuro estimular a escalada entre as mulheres para nos fortalecer" (S3). "Acho que um grupo de mulheres tende a incentivar umas às outras de um jeito específico, que é difícil encontrar com os parceiros homens, é uma relação mais afetiva" (S19). "Me sinto mais acolhida e livre em um ambiente só de mulheres" (S44). "Gosto bastante de escalar apenas com outras mulheres, pois estou começando e elas são pacientes para me levar para vias de menor grau e isso me deixa confortável" (S20). "Pertenço a um grupo de mulheres que escalam, desde iniciantes às mais experientes. Isso me incentiva e me dá conforto na hora de escalar" (S79). "As mulheres se entendem em relação às dificuldades do esporte e, portanto, se ajudam mais" (S208). "Em relação à escalada, não vejo problema nenhum em viajar para escalar somente com mulheres. Em relação à segurança geral no Brasil, sim, me sinto desconfortável em ir a alguns locais em grupo estritamente feminino" (S11). "Quando o grupo é exclusivamente feminino, naturalmente buscamos mais informações de segurança da região e possibilidades diversificadas de apoio. O problema não é a viagem, escalada com mulheres do ponto de vista técnico, mas a convivência rotineira das mulheres com situações de ameaça (majoritariamente masculinas) que geram insegurança, em qualquer ambiente" (S14). "Eu nunca viajei só com mulheres, mas seria o meu sonho" (S26). "Nunca fui só com mulheres, mas seria bem agradável. Mesma linguagem e tal" (S50).

- Tensões entre gêneros: "As meninas têm ganhado muita força e vontade de escalar nos últimos tempos, o que me deixa extremamente confortável para crescer junto e estar no mesmo ambiente que mulheres escaladoras, por entender que são todas igualmente capazes de, não só escalar, mas entender dos procedimentos básicos tanto quanto os homens" (S253). "Acho que a mulherada tem que se apoiar" (S228). "Há cerca de uma semana criei um grupo só de meninas - Cerrado Climb Girls - e tem dado resultado. $\mathrm{O}$ intuito dele é reunir escaladoras e incentivar meninas a fim de conhecer o esporte, além de ser um grupo de empoderamento feminino, claro" (S234), "E por que não sentiria? Mulheres unidas, na vida e na escalada, é tudo de bom e mais um pouco" (S125). "Sororidade" (S168). "Se não consegue isolar o move $^{2}$ eles ficam dando betas ${ }^{3}$ e betas que por vezes não nos ajudam (...) limitando assim a evolução na leitura de vias e também no reconhecimento de nossos limites. Sem falar da série de comentários machistas" (S184). "O que difere os homens das mulheres na escalada, pra mim, é a diferença biológica de força física, que pode ser trabalhada e a cultura da sociedade homem x mulher" (S164). "Não tem diferença entre mulher ou homem, o que importa é o conhecimento da prática" (S6).

\section{DISCUSSÃO}

A idade média superior a 30 anos demonstra longevidade neste esporte e o IMC médio indica uma boa qualidade de vida, afinal "[...] é um indicador relativamente bom

\footnotetext{
2 Isolar o move é conseguir fazer um movimento específico que a pessoa tem dificuldade.

3 Betas são dicas que se recebe de outro escalador ou escaladora.
} 
da composição corporal total, [...] este índice tem sido recomendado pela Organização Mundial da Saúde como um indicador da gordura corporal, por ser obtido de forma rápida e praticamente sem custo nenhum" (FONTOURA; FORMENTIN; $\mathrm{ABECH}, 2009$, p. 87). Sendo assim, a prática da escalada provém as mulheres de boas condições de saúde. Além disso, a verificação do grau técnico das escaladoras mostrou que escalar acima de $8^{\circ}$ grau diminui ainda mais o IMC e o medo das escaladoras, mas para atingir esses benefícios é necessário aumentar a quantidade de prática e manter a regularidade. Pereira e Manoel (2008) apontaram que escaladores experientes têm em média pelo menos cinco anos de prática e que esse tempo é necessário para suportar treinamentos intensos e elevar o índice técnico.

A escalada em vias esportivas é a preferida das escaladoras, envolvendo superar dificuldades técnicas e físicas em rochas com altura aproximada de dez metros até 30 metros. As vias possuem proteções fixas com grampos, minimizando risco de acidentes e quedas.

\begin{abstract}
Esse estilo surgiu no início da década de 1980 como uma forma de treinamento físico e técnico para escaladores de alta montanha. Porém, com o decorrer dos anos ele ganhou adeptos próprios em virtude da sua maior acessibilidade, comparado às escaladas alpinas (BERTUZZI; LIMASILVA, 2013, p. 6).
\end{abstract}

Revelou-se a presença de mais da metade da escaladoras em paredes artificiais, pois os ambientes controlados em relação às questões climáticas, a proximidade dos centros urbanos, a segurança e pessoas capacitadas para a instrução são fatores que levam as mulheres a esse tipo de atividades (MARINHO; BRUHNS, 2001; PEREIRA, 2018). Apesar do número pequeno de mulheres realizando a escalada de big wall, é importante revelar sua presença, afinal essa modalidade ocorre em paredes, geralmente, acima de 600 metros, utilizando materiais artificiais para ascender e logística para muitos equipamentos, pernoite, higiene e alimentação. "É sem dúvida um estilo mais rústico do que as demais, exigindo logística, capacidade de organização, trabalho em equipe, certa perícia, um bom julgamento das ações e perseverança" (BERTUZZI; LIMA-SILVA, 2013, p. 9).

Os clubes, academias e associações de escalada, incluindo a Associação Brasileira de Escalada Esportiva (ABEE), contribuem como grandes fomentadores e difusores das praticantes, servindo de base para a evolução técnica e física, além de serem ambientes propícios para trocas de experiências e espaços de motivação e criação de vínculos (CARVALHO, 2014).

Tal qual em outras modalidades esportivas, a escalada concentra o maior número de participantes nas regiões mais ricas do país, o que conduz a ideia de elitização da escalada e do esporte em geral (PNUD, 2017).

A força é identificada como o maior benefício adquirido na escalada, de acordo com Cruz et al. (2012), pode-se notar nos praticantes da escalada:

[...] melhora na resistência e tônus muscular de todo o corpo, sem um aumento sensível em sua massa. Um grande senso de equilíbrio, controle motor e alongamento também são desenvolvidos, além de moldar um espírito de superação muito importante, pois os limites são frequentemente alcançados e somente ao reconhecer e superar as próprias deficiências é que o escalador conseguirá progredir (p.11). 
Além da força física, como vantagem principal, os aspectos socioemocionais se destacaram, sendo a percepção sobre a amizade, confiança, coragem, concentração e autoestima as mais relevantes, pois o risco e o perigo de queda e acidente são entendidos como fatores limitantes e que podem ser superados com a autoconfiança e o aumento da coragem. Vale observar o estudo de Burnik, Jug e Kajtna (2008) em que não encontraram diferenças entre homens e mulheres no aspecto arriscar-se na escalada, o que demonstra que as mulheres superam o medo tanto quanto os homens. Pereira (2013), em estudo apenas com homens, verificou que o medo é uma constante, especialmente quando o local escalado é uma novidade, pois com menos conhecimento sobre a via, aumentamse as possibilidades de quedas, e neste aspecto, enfrentar a adversidade é um componente apreciado por quem escala.

Compreende-se que à medida que se evolui na graduação da escalada, há diminuição na percepção do medo, pois a experiência, o aumento de força, de confiança e a evolução técnica desenvolvem as qualidades físicas e psicológicas, gerando autocontrole. Esse desempenho das praticantes pode ser confirmado por Monteiro e Bonone (2014, p. 3): "[...] a prática de exercício físico melhora não somente a condição fisiológica do indivíduo, como também o bem-estar psicológico, como a melhora nas interações sociais, no autocontrole e na autoestima".

A prática de outras atividades físicas como yoga, pilates, musculação, ginástica, natação e esportes de quadra revela uma preocupação com o exercício físico como integrando a vida dessas pessoas e auxiliando no bom desempenho específico da modalidade, corroborando Pereira et al. (2019).

Sobre as tensões a respeito da aceitação da mulher pelo homem na escalada ficou evidente que a mulher precisa lidar com o quantitativo maior masculino como ponto de partida, e isto influi na percepção e na construção social do esporte para elas. Plate (2007) destaca o próprio estranhamento, quando confrontada por um homem em relação a seu desempenho superior ao de homens na escalada, para ela, os objetivos de homens e mulheres na escalada são um pouco diferentes, com as mulheres focando-se nas relações com o meio e com as pessoas, enquanto os homens ficam mais interessados em seus feitos e desafios pessoais, o que explica em parte seus desempenhos mais satisfatórios.

Por outro lado, observou-se o predomínio dos homens em acolher a mulher no esporte, o que é positivo, mesmo assim, $1 / 4$ delas admitiu sentir-se desprezada ou com atitude indiferente por parte dos homens, evidenciando que a falta de acolhida desmotiva sua participação. Esta informação contrasta com a grande maioria de mulheres que informou ser incentivada por homens a evoluir na parte técnica e física e com o encorajamento na montagem de vias no ambiente indoor, talvez isso ocorra pela necessidade do homem de um parceria e quando a mulher corresponde, isso o ajuda a praticar e evoluir no esporte. O conflito entre apoios e rejeições que a mulher sente dos homens na escalada demonstra, tal qual apresentam Silva, Gomes e Queiróz (2006), que não se trata de polarizar o tema em torno da diferença biológica homem/mulher, mas de olhar para as tensões em suas dimensões sociais e culturais, pois diversas participantes do estudo afirmam 
se sentir bem escalando com homens, que eles a incentivam e que é encorajada por eles, como se vê no Quadro 3.

Entende-se que por razões pessoais ele aceita a mulher como acompanhante na escalada, e isso provavelmente justifique o percentual muito reduzido de mulheres que pratica o big wall, que é a escalada mais comprometedora do ponto de vista de riscos e de exigências técnicas, psicológicas e físicas. Como dito por Vilanova e Soler (2008), a escalada é um espaço de negociação para que a mulher conquiste, não apenas as vias, mas a desconstrução dos estereótipos de gênero. O estudo histórico da inserção da mulher no esporte, no Brasil, demonstra este papel secundário e limites às ações da mulher reforçando estigmas.

\begin{abstract}
O incentivo a uma maior inserção das mulheres em diferentes instâncias culturais continha, em si mesmo, discursos emancipatórios e conservadores, pois, ao mesmo tempo em que incentivavam as mulheres à adesão à prática de atividades físicas, através destas reforçavam uma representação hegemônica de feminilidade (GOELLNER, 2008, p. 23).
\end{abstract}

A maioria das escaladoras mostrou-se disposta a viajar e escalar somente com mulheres. Na categoria técnica, a experiência no domínio dos procedimentos, principalmente pelos riscos, é um elemento fundamental na escolha de parceiros, e as mulheres acabam confiando nos homens, por não sentirem que outras mulheres se dedicam tanto ao esporte. Entende-se que o menor número de mulheres e o menor domínio da escalada guiada e de outros procedimentos interferem diretamente nessas escolhas, tornando as mulheres dependentes do maior poder dos homens neste campo (PLATE, 2007).

O componente familiar não foi o mais citado, todavia, o esposo ou namorado é lembrado como parceiro, mas nenhuma delas citou escalar com a filha, irmã ou mãe. Evidenciou-se também a falta de oportunidade que a mulher tem na escalada, na categoria socioemocional, além de algumas se sentirem como possíveis vítimas de violência em locais isolados como as rochas. Por fim, entre as que não se sentem confortáveis, apenas com mulheres na escalada em rocha, a questão biológica, da menor força, foi compreendida como relevante no caso de um acidente, para preferir homens numa viagem, deixando claro que resistir aos estereótipos da feminilidade, da aparência, da cuidadora e do pouco empenho é um entrave à escalada feminina (APPLEBY; FISHER, 2005).

$\mathrm{Na}$ questão técnica e familiar, foi afirmado que homens, em geral, podem se dedicar mais e isso lhes possibilita desenvolver-se com mais qualidade. $O$ cuidado da mulher com os filhos e outros afazeres torna a comparação injusta, como foi dito por uma delas. Superar o medo e ganhar confiança para melhorar o desempenho vem com a prática, independentemente se é homem ou mulher. A presença do marido como parceiro é um modo de aproximação com o esporte, mas as mulheres aventam outros voos mais livres em algumas falas. Schwartz et al. (2013) apontam que grupos específicos de mulheres que se apoiam nas práticas esportivas de aventura - e, no caso da escalada, esses grupos existem 4 - podem ser formas de acesso e efetivação da participação das mulheres no esporte. Mourão (2000), olhando para a participação da mulher no esporte, afirma que quando a família encoraja a mulher a uma vida esportiva há maior chance dela se tornar uma praticante efetiva.

4 Escalada das manas e Minas no Boulder são grupos das redes sociais somente de mulheres. 
$\mathrm{Na}$ categoria socioemocional percebe-se que, para as entrevistadas, realizar viagens com apenas mulheres pode trazer benefícios, como: ser um incentivo maior, um ambiente de amizade contagiante, receptivo, com boa energia, experiência afirmativa e identificação. A cumplicidade de fazer parte de um grupo parece tornar ainda mais prazeroso esse momento, com menos julgamentos pelo desempenho, como evidenciado por Plate (2007). O que elas ressaltam por um ponto negativo é serem vítimas de violências, fora do aspecto esportivo e se sentirem vulneráveis a assédios por parte dos homens.

Sobre as tensões entre gêneros, para muitas escaladoras esse empoderamento feminino no esporte deve ser apoiado por elas, seja em atividades exclusivas femininas ou não. Para Appleby e Fisher (2005), mulheres de destaque na escalada podem auxiliar as iniciantes a superar as normas sociais que colocam a mulher em papel inferior. O sentimento de inferioridade ficou evidente em algumas respostas e apareceu o desconforto de ser biologicamente menos favorecida em força, nada que uma cultura de equidade não possa reverter. Finalizando, algumas respostas foram no sentido de mostrar que a diferença não está no gênero e sim na experiência de quem escala, nestes casos, ocorre uma negação à construção sócio-histórica do esporte, relativizando uma vantagem do gênero masculino sobre o feminino.

\section{CONCLUSÃO}

A presente pesquisa atendeu a proposta, conseguindo apresentar um perfil das escaladoras brasileiras. Verificou-se que o número de praticantes cresceu e descobriu-se que o maior desejo delas é escalar em ambientes naturais, entretanto, é bem significativa a participação delas em ambientes artificiais como modo de preparação para os desafios encontrados na rocha, servindo de treinamento de movimentos específicos que contribuem para a evolução no esporte feminino. Destacam-se, também, os benefícios físicos e emocionais adquiridos na escalada, sendo as amizades formadas entre elas o componente principal de estímulo para progredirem num esporte onde há a predominância dos homens como praticantes e o risco de acidentes, sendo um componente de desafio que as mulheres estão dispostas a superar.

Mesmo quando não são bem recebidas por eles, encontrando dificuldades por parte de alguns, as mulheres não se deixam intimidar, buscam formas de desenvolver habilidades que permitiam atravessar seus desafios pessoais. Acreditase que aprender técnicas e habilidades específicas da escalada é um caminho para a satisfação e independência no esporte.

O compartilhamento de experiências e emoções entre as mulheres parece um passo decisivo para que se sintam confortáveis e adquiram experiência suficiente para se manterem motivadas a avançar na escalada, e possam ter como referência as próprias mulheres. Espera-se que este estudo contribua e estimule novas pesquisas sobre a participação da mulher na escalada brasileira. 


\section{REFERÊNCIAS}

APPLEBY, Karen M.; FISHER, Leslee A. "Female energy at the rock": A feminist exploration of female rock climbers. Women in Sport and Physical Activity Journal, v. 14, n. 2, p. 10 23, 2005.

BARDIN, Laurence. Análise de conteúdo. São Paulo: Edições 70, 2008.

BERTUZZI, Rômulo de Cássia Moraes; LIMA-SILVA, Adriano E. Principais características dos estilos de escalada em rocha e indoor. Revista Acta Brasileira do Movimento Humano, v. 3, n.3, p.31-46, jul./set. 2013.

BURNIK, Stojan; JUG, Snezana; KAJTNA, Tanja. Sensation seeking in slovenian female and male mountain climbers. Acta Universitatis Palackianae Olomucensis. Gymnica, v. 38, n. 3, p. $15-19,2008$.

CARVALHO, Alessandra Izabel. Práticas de natureza: movimento e contemplação nas montanhas do Marumbi. Antíteses, v. 7, n. 13, p. 415 - 439, jan./jun. 2014.

CRUZ, Marina S.; GRANADO, Carolina Aparecida C.; DIAS, Gisele P. A Escalada Esportiva utilizada por amputados de membro inferior como meio para integração social e desenvolvimento pessoal. Arquivos em Movimento, v. 8, n.1, p. 8- 21, jan/jun. 2012.

FONTOURA, Andréa Silveira de; FORMENTIN, Charles Marques; ABECH, Everson Alves. Guia prático de avaliação física: uma abordagem didática, abrangente e atualizada. São Paulo: Phorte, 2009.

GIGLIO, Sergio S.; GALATTI, Larissa R.; MACHADO, Gisele V.; ALTMANN, Helena; PAES, Roberto R.; SEONE, Antonio M. Desafios e Percalços da Inserção da Mulher nos Jogos Olímpicos (1894-1965). Revista de História do Esporte, v. 11, n.1, p. 1-22, 2018.

GOELLNER, Silvana. "As mulheres fortes são aquelas que fazem uma raça forte": esporte, eugenia e nacionalismo no Brasil, no início do século XX. Recorde, Revista de História do Esporte, v. 1, n. 1, p. 1 - 28, jun. 2008.

LIKERT, Rensis. A technique for the measurement of attitudes. Archives in Psychology, v. 140, p. 1 - 55, 1932.

MARINHO, Alcyane; BRUHNS, Heloisa Turini. Escalada urbana: faces de uma identidade cultural contemporânea. Movimento, v. 7, n. 14, p. 37 - 48, 2001.

MONTEIRO, Carine Maciel; BONONE, Carlos Gabriel. Os fatores psicológicos no desempenho de escaladores esportivos amadores de Caxias do Sul - RS. Do Corpo, Ciências e Artes, v. 4, n. 1, 2014.

MOURA, Giovanna Xavier de; STAREPRAVO, Fernando Augusto; ROJO, Jeferson Roberto; TEIXEIRA, Dourivaldo; SILVA, Marcelo Moraes e. Mulher e esporte: o preconceito com as atletas do Rugby na cidade de Maringá-PR. Motrivivência, v. 29, n. 50, p. 17 - 30, 2017.

MOURÃO, Ludmila. Representação social da mulher brasileira nas atividades físicodesportivas: da segregação à democratização. Movimento, ano 7, n. 13, p. 5-18, 2000.

PEREIRA, Dimitri W. Revelando a escalada em paredes artificiais. Corpoconsciência. v. 22, n. 2, p-61-72, mai./ago. 2018.

PEREIRA, Dimitri W.; ARMBRUST, Igor. Pedagogia da aventura: os esportes radicais, de aventura e de ação na escola. Jundiaí- SP: Fontoura, 2010. 
PEREIRA, Dimitri W.; CASANOVA, Roberto Dinato; ALMEIDA, Marcos Vinicius Nascimento; PRADO, Diogo Henrique Lima. Escalada esportiva no Brasil: O retrato dos atletas profissionais e amadores. Arquivos em Movimento, v. 15, n. 1, p. 241 - 255, jan./jul. 2019.

PEREIRA, Dimitri W.; MANOEL, Mario Lucas. O Treinamento de Escaladores de Competição do Estado de São Paulo. Revista Mineira de Educação Física, v. 16, n. 2, p. $108-135,2008$.

PEREIRA, Leonardo Madeira. Estados emocionais de estresse e cortisol salivar na escalada em rocha. 2013. 113 f. Tese (Doutorado em Ciências da Motricidade) - Instituto de Biociências de Rio Claro, Universidade Estadual Paulista, Rio Claro, 2013.

PLATE, Katharine R. Rock climbing is a masculine sport? Understanding the complex gendered subculture of rock climbing. Sheffield Online Papers in Social Research, 2007. Disponível em: https://www.sheffield.ac.uk/polopoly_fs/1.71699!/file/10-Plate-article.pdf. Acesso em: 20 mar. 2020.

PNUD - PROGRAMA DAS NAÇÕES UNIDAS PARA O DESENVOLVIMENTO. Relatório de Desenvolvimento Humano Nacional - Movimento é Vida: Atividades Físicas e Esportivas para Todas as Pessoas. Brasília, 2017. Disponível em: https://www.br.undp.org/content/ brazil/pt/home/library/idh/rdhs-brasil/relatorio-nacional-desenvolvimento-humano-2017.html. Acesso em: 29 mar. 2017.

SCHWARTZ, Gisele M.; FIGUEIREDO, Juliana P.; MADEIRA, Leonardo M.; CHRISTOFOLETTI, Danielle F. A.; DIAS. Viviane K. Preconceito e esportes de aventura: A (não) presença feminina. Motricidade, v. 9 n. 1, p. 57 - 58, 2013.

SEVERINO. Antônio Joaquim. Metodologia do trabalho científico. 23. ed. rev. atual. São Paulo: Cortez, 2007.

SILVA, Paula; GOMES, Paula Botelho; QUEIRÓZ, Paula. Educação Física, Desporto e Género: o caminho percorrido na Faculdade de Desporto da Universidade do Porto (Portugal). Movimento, v. 12, n. 1, p. $31-58$, jan./abril, 2006.

VILANOVA, Anna; SOLER, Suzanna. Las mujeres, el deporte y los espacios públicos: Ausencias y protagonismos. Apunts - Educación Física y Deportes, n. 1, jan./mar. p. 29 $34,2008$. 
Abstract: Climbing poses risks and challenges that require physical and emotional skills. Each day, women appropriate this culture in Brazil. This study outlines the profile of Brazilian female climbers and their perceptions about their acceptance in that sport. It used the exploratory method, with a questionnaire answered by 268 female climbers. It found that they achieve good quality of life due to physiological, social and emotional aspects. The practice of climbing makes women confident and autonomous depending on their physical and technical performance. For them, climbing is a space for overcoming, which goes beyond the vertical environment. The study concludes that the number of women practicing climbing in Brazil has increased, which shows that even in adverse situations they remain in the sport, seeking independence and the advancement of women's sport.

Keywords: Sports; Women; Aptitude.

Resumen: La escalada presenta riesgos y desafíos, que requieren habilidades físicas y emocionales. Todos los días las mujeres toman posesión de esta cultura en Brasil. El objetivo de esta investigación fue delinear un perfil de las escaladoras brasileñas y su percepción de su aceptación en el deporte. El método utilizado fue exploratorio con un cuestionario para 268 escaladoras. Como resultado, se identificó que las escaladoras adquieren una buena cualidad de vida, debido a aspectos fisiológicos, sociales y emocionales. La práctica de la escalada confiere confianza y autonomía a la mujer em función del rendimento técnico y físico. La escalada, para ellas, muestra un espacio de superación que va más allá del entorno vertical. Se concluye que el número de mujeres em la escalada ha aumentado em Brasil, lo que demuestra que incluso ante situaciones adversas, se mantienen firmes en la modalidad buscando la independencia y la evolución del deporte feminino.

Palabras clave: Deportes; Mujeres; Aptitud. 


\section{LICENÇA DE USO}

Este é um artigo publicado em acesso aberto (Open Access) sob a licença Creative Commons atribuição Não Comercial 4.0 (CC BY 4.0), que permite uso, distribuição e reprodução em qualquer meio, desde que o trabalho original seja corretamente citado, com a restrição que impede o uso para fins comerciais. Mais informações em: http://creativecommons.org/licenses/by-nc/4.0

\section{CONFLITO DE INTERESSES}

Os autores declararam que não há conflito de interesses neste trabalho.

\section{CONTRIBUIÇÕES AUTORAIS}

Dimitri Wuo Pereira: definição do objeto de estudo, revisão de literatura, criação da metodologia, análise de resultados, conclusão, digitação do texto.

Yasmin Brito Souto Maior: definição do objeto de estudo, revisão de literatura, realização da pesquisa de campo, análise dos resultados, discussão, digitação do texto.

Bianca Trovelo Ramallo: criação de metodologia, análise de resultados e revisão do texto.

\section{FINANCIAMENTO}

O presente trabalho foi realizado sem qualquer apoio financeiro.

\section{ÉTICA EM PESQUISA}

A pesquisa foi aprovada pelo comitê de ética da Universidade Nove de Julho, conforme parecer 882.781 .

\section{COMO REFERENCIAR}

PEREIRA, Dimitri Wuo; SOUTO MAIOR, Yasmin Brito; RAMALLO, Bianca Trovelo. Perfil das mulheres escaladoras brasileiras, entre homens e montanhas. Movimento, v. 26, p. e26077, jan./dez. 2020. Disponível em: https://seer.ufrgs. br/Movimento/article/view/100848. Acesso em: 28 nov. 2020. DOI: https://doi. org/10.22456/1982-8918.100848

\section{RESPONSÁVEIS EDITORIAIS}

Alex Branco Fraga*, Elisandro Schultz Wittizorecki*, Ileana Wenetz ${ }^{* *}$, Ivone Job*, Mauro Myskiw*, Raquel da Silveira*

*Universidade Federal do Rio Grande do Sul, Escola de Educação Física, Fisioterapia e Dança, Porto Alegre, RS, Brasil

**Universidade Federal do Espírito Santo (UFES). Centro de Educação Física e Desportos (CEFD), Vitória/ES, Brasil 